\title{
Strontium Ranelate Using for the Treatment of Postmenopausal Osteoporosis
}

\author{
Ahmad Oryan ${ }^{1}$, Somayeh Monazzah ${ }^{2}$ and Amin Bigham-Sadegh*3 \\ ${ }^{1}$ DVM in Comparative pathology, Department of Pathology, Shiraz University, Iran \\ ${ }^{2}$ DVM Student of Veterinary Pathology, Department of Pathology, Shiraz University, Iran \\ ${ }^{3}$ DVM in Veterinary Surgery, Department of clinical Sciences, Shahrekord University, Iran
}

Received: April 04, 2018; Published: June 14, 2018

*Corresponding author: Amin Bigham-Sadegh, DVM, DVSc, Department of Clinical Sciences, School of Veterinary Medicine, Shahrekord University, Shahrekord, Iran

\begin{abstract}
The main reason of postmenopausal osteoporosis is high bone turnover due to increased osteoclastic action. Strontium Ranelate is a new drug that is used for the treatment of postmenopausal osteoporosis. We searched PubMed in May 2016 using the terms 'Strontium ranelate' for experimental study and review articles. The result from the studies that we have conciliated show: Strontium ranelate enhances bone resistance and increases the bone formation. Strontium ranelate has been shown to increase bone apposition rates and bone mineral density while maintaining the quality of bone mineral; but it has no effect on mineralization. Evidence from in vitro and in vitro studies present the evidence that strontium ranelate is able to inhibit the osteoclasts resorbing activity, decreased osteoclastic differentiation (Prevention of differentiation of blood monocyte and pre-osteoclasts into osteoclasts) and increase apoptosis of osteoclasts. The studies show that strontium ranelate increased pre-osteoblastic replication and osteoblastic proliferation and differentiation as evaluated by the measurement of DNA synthesis in osteoblasts.

Strontium ranelate stimulated the synthesis of PG by human chondrocytes. Strontium ranelate promotes the synthesis of PG capable of integrating the ECM. It has been show that post fracture use of strontium ranelate on the ovariectomized rats is associated with better fracture healing as assessed by radiography, histological analysis and biomechanical testing. The exact mechanism by which strontium ranelate exerts these effects is not definitely understood, but may include inhibition of osteoclast formation and stimulation of osteoblast proliferation. In most cases use of strontium ranelate did not seem to be associated with series adverse events and most adverse events were mild and transient. It seems that Strontium ranelate is aeffective and winsome treatment for osteoporosis and in the most cases the side effect of this drug is negligible.
\end{abstract}

Abbreviations: SOTI: Spinal Osteoporosis Therapeutic Intervention; TROPOS: Treatment of Peripheral Osteoporosis; STRATOS: Strontium Ranelate for Treatment of Osteoporosis; PREVOS: Prevention of Osteoporosis

\section{Introduction}

The main reason of postmenopausal osteoporosis is high bone turnover due to increased osteoclastic action) [1]. Strontium Ranelate is a new drug that is used for the treatment of postmenopausal osteoporosis [2]. It is used for decreasing the risk of fracture in vertebral and non-vertebral (especially hip) bones [3]. Strontium ranelate is a combination of strontium chloride $(\mathrm{SrCl} 2,6 \mathrm{H} 20)$ and sodium ranelate [4]. Strontium ranelate contains two stable atoms, strontium and one organic carrier, ranelic acid [5]. The molecular action mechanism of strontium ranelate is not understood [4]. But its action mechanism on bone is complex and time-dependent and dose- dependent [6]. It has been seen that the low doses of strontium ranelate persuaded the bone tissue quality [7]. It enhances bone tissue quality, and is effective on bone resistance and reduces the fracture risk in postmenopausal osteoporotic patients which treated with strontium ranelate [8].

Strontium ranelate also prevents bone loss that is induced by estrogen deficiency in postmenopausal women by restraint of bone resorption and stimulation of bone formation [9]. In ovariectomized rats, Strontium ranelate prevented bone resorption, whereas bone formation remained elevated [10]. This drug is well tolerated because it has no effect on food intake or body weight [11]. Strontium ranelate has some similarities with $\mathrm{Ca}+2$ in its absorption in the digestive system, incorporation into bone, and reabsorption in the kidneys [12]. Because strontium, a divalent cation like $\mathrm{Ca}+2$, it's possible that the ralenate salt plays a role in the incident of this reaction [13]. Administration of $2 \mathrm{~g}$ /day of strontium ranelate to 
postmenopausal women for a 2-year resulted in uncoupling between bone resorption and bone formation that led to a significant increase in the lumbar spine bone density and a $44 \%$ reduction in vertebral fracture during the 2end year of treatment [14]. The strontium ranelate effects on bone can be studied by histomorphometry, DXA, and biomechanics in preclinical studies [15]. Originally strontium was detected in the 1700, in Scotland, a place near Strontian [16]. This earth element is present in food and water and throughout the bones [17]. Strontium ranelate was used widely in the 1950 for the treatment of malignant bone diseases, osteoporosis, painful, etc. [18].

\section{Material and Method}

We searched PubMed in May 2016 using the terms 'Strontium ranelate' for experimental study and review articles. Of the 61 articles retrieved, there were 5 review articles. Evidence of the safety and efficacy of strontium ranelate comes from two large multinational clinical trials, the Spinal Osteoporosis Therapeutic Intervention (SOTI), [5] and Treatment of Peripheral Osteoporosis (TROPOS), [19] studies, which were designed to study vertebral and non vertebral fractures respectively; and clinical data is available from 2 earlier Phase 2 trials, the Strontium Ranelate for Treatment of Osteoporosis (STRATOS), Meunier et al. and Prevention of Osteoporosis (PREVOS), [18] studies.

\section{The Effects of Strontium Ranelate on Bone}

Strontium ranelate cause a positive bone balance in experimental models [13]. It has a unique effect on bone remodeling by increasing bone formation and decreasing bone resorption, which leads to prevention of bone loss and increase in bone mass and strength [20]. It increases markers of bone formation and also has anabolic effects on bone [21]. The analysis of bone markers showed that strontium ranelate reduced the excretion of the bone resorption marker from kidney and increased the levels of osteoblast differentiation serum marker, bone-specific alkaline phosphatase [22]. Strontium ranelate enhances bone resistance and increases the bone formation, as evaluated by increased ALP activity, and it is confirmed by the increased trabecular and cortical bone tissue amount [23].

Strontium ranelate has been shown to increase bone apposition rates and bone mineral density while maintaining the quality of bone mineral [24]; but it has no effect on mineralization [25]. Actually some studies on intact animals confirm that strontium ranelate preserves the structure of bone matrix crystals without affecting the mineralization process [26]. It has been shown that treatment with strontium ranelate results in the formation of lamellar bone with no evidence of mineralization defect or other deleterious effects [27].

a) It has shown strontium ranelate increase the diameter of the bone shaft suggesting an effect on periosteal bone formation [28]. It also increases trabecular bone volume, trabecular number, trabecular thickness, and cortical thickness Arlot et al. Modification of bone diameters with periosteal apposition may effects bone strength of long bones [29]. This effect on bone size is very important and can play a role in the improve- mentof mechanical properties of bone, because the diameter of long bones predicts to $55 \%$ of the variance of the bone strength (Arlot et al 2008). Strontium ranelate treatment seems to stimulate both trabecular and cortical bone formation in 3D analyses but without increase of cortical porosity [30]. The change in 3D trabecular and cortical micro architecture improve bone biomechanical properties Arlot et al.

b) Evidence from in vitro and in vitro studies present the evidence that strontium ranelate is able to inhibit the osteoclasts resorbing activity [31], decreased osteoclastic differentiation (Prevention of differentiation of blood monocyte and pre-osteoclasts into osteoclasts) and increase apoptosis of osteoclasts [5]. Strontium ranelate inhibited the expression of two osteoclast markers: the $\alpha \mathrm{v}$ subunit of the vitronectin receptor and carbonic anhydrase-II in bone marrow culture [32].

c) The studies show that strontium ranelate increased pre-osteoblastic replication and osteoblastic proliferation and differentiation as evaluated by the measurement of DNA synthesis in osteoblasts [9]. It stimulates osteoblastic differentiation markers activity such as ALP, bone sialoprotein and osteocalcin in osteoblasts [16]. Strontium ranelate promote osteoblasts survival [33] and its positive effects on osteoblast survival, is because of the seven-transmembrane-spanning extracellular calcium-sensing receptor which is expressed by osteoblasts and that responds to strontium [34]. However, recently it has been showed which Strontium ranelate increases osteoblasts survival independently of the calcium-sensing receptor, indicate that other signaling mechanisms may involve in the positive effects of Strontium ranelate on osteoblastogenesis [35].

d) Some in vitro Studies in human osteoblasts suggest that strontium ranelate have the ability to promote the differentiation and survival of osteocytes, which is an additional mechanism of its anti-fracture efficacy [10].

e) Strontium ranelate has beneficial effects on both cartilage and bone remodeling Henrotin et al. It has shown evidence of beneficial effects of strontium ranelate on interference in cartilage metabolism [36]. It stimulates cartilage matrix formation by ionic stimulation of chondrocyte anabolism without affecting resorption of cartilage; it enhanced collagen synthesis and has a direct effect on proteoglycan synthesis [37]. It could restore the imbalance between chondroresorption and chondroformation observed.

f) Strontium ranelate stimulated the synthesis of PG by human chondrocytes [38]. Strontiumranelate promotes the synthesis of PG capable of integrating the ECM [39]. It also promoted the synthesis of high-molecular weight PG complexes [40]. The mechanism that strontium ranelate influenced the synthesis of PG is not known until now Henrotin et al. Strontium is effective in reversing the IGF-Istimulating effect, because factors which lead to increase the synthesis of PG were reported as causing an initial decrease in cytosolic free Ca concentration [41]. IGF-I stimulation of PG synthesis maybe increased by 
strontium ranelate treatment [42]. This effect may be consequent to the proliferation of chondrocyte because IGF-I is required for cell proliferation [43]. This fact that IGF-I regulates the metabolism of chondrocyte (by IGF-I produced in response to a high of strontium) can be responsible for the PG increase [44]. Furthermore high extra cellular Ca concentration increases the secretion of IGF-I as well as the expression of IGF-I mRNA by osteoblastic MC3T3-E1 cells [45]. This finding can explain why strontium ranelate increased the IGF-I effect when it was added to a low concentration [36].

Fracture Healing: Although antifracture efficacy of strontium ranelate has been demonstrated, there is paucity of data on the effect of strontium ranelate on fracture healing [4] and there are limited data about the effect of strontium ranelate on fracture healing Seeman et al. It has been show that post fracture use of strontium ranelate on the ovariectomized rats is associated with better fracture healing as assessed by radiography, histological analysis and biomechanical testing Seeman et al. Some of scientists evaluated the efficacy of strontium ranelate on fracture healing in healthy bone Roux et al. In these studies employing traumatically induced fracture, no effect on fracture healing were reported Arlot et al. \& but $\mathrm{Li}$ et al. reported that $625 \mathrm{mg} / \mathrm{kg} /$ day strontium ranelate revealed beneficial effect on the fracture healing on the ovariectomized rats [24]. The weaker antiresorptive activity of strontium ranelatecan not disrupts the osteoclast resorption in the remodeling phase [19]. Anabolic activity of strontium ranelate can provide beneficial effect on the regenerative and reparative processes of the remodeling phase in the fracture healing (Roux et al 2016). Further studies are needed to discover the precise mechanism of action of strontium ranelate on fracture healing [19] (Table 1).

Table 1: the results of different study about strontium ranelate.

\begin{tabular}{|c|c|c|c|c|}
\hline No & Scientist & Year & Model & Result \\
\hline 1 & Farlay & 2005 & In Vivo/Monkeys & Confirming the positive histomorphometric change in bone structure \\
\hline 2 & Seeman et al. [5] & 2006 & In Vivo/Women & Safely reduces the risk of vertebral and non-vertebral fractures \\
\hline 3 & Henrotin & 2001 & In Vitro & $\begin{array}{l}\text { Stimulated PG production, Increased the stimulatory effect of IGF-I (1029 M) on } \\
\text { PG synthesis, Stimulates human cartilage matrix formation }\end{array}$ \\
\hline 4 & Ammann et al. [4] & 2007 & In Vivo/Rats & $\begin{array}{l}\text { Direct action on bone tissue quality, Improves bone tissue quality, Increase in bone } \\
\text { strength, Reduction of fracture risk }\end{array}$ \\
\hline 5 & Roux et al. [5] & 2006 & In Vivo/Women & Anti-vertebral fracture efficacy \\
\hline 6 & Bolland mj \& greya [13] & 2014 & Librarian & The risks of strontium use are similar to the benefits \\
\hline 7 & Seeman et al. [5] & 2008 & In Vivo/Women & Reduces the risk of vertebral fractures \\
\hline 8 & Reginster et al. [3] & 2016 & In Vivo/Women & Significant effect on structure in patients with knee osteoarthritis \\
\hline 9 & Kaufman et al. [22] & 2013 & In Vivo/Men & Treatment of osteoporosis in men. \\
\hline 10 & Grosso & 2008 & Librarian & No evidence of aforementioned potentially life-threatening adverse events. \\
\hline 11 & Carvalho & 2011 & In Vivo/Women & rapid bone anabolic effect on unhealed atypical fractures \\
\hline 12 & Arlot & 2008 & In Vivo/Women & $\begin{array}{l}\text { Higher mineral apposition rate, Borderline higher in cortical bone, Osteoblast } \\
\text { surfaces were significantly higher, Significant changes in micro architecture, High- } \\
\text { er cortical thickness and trabecular number, Lower structure model index and } \\
\text { trabecular separation, No change in cortical porosity, Enhance bone biomechani- } \\
\text { cal competence, Decreased fracture rate }\end{array}$ \\
\hline 13 & Brennan et al. [24] & 2009 & In Vitro & Anti-fracture effect, anabolic and anti-resorptive actions \\
\hline 14 & Borgstrom & 2006 & In Vivo/Women & $\begin{array}{l}\text { Strontium ranelate is cost-effective in the treatment of postmenopausal women } \\
\text { with low BMD }\end{array}$ \\
\hline 15 & Reginster et al. [19] & 2005 & In Vivo/Women & $\begin{array}{l}\text { Significantly reduction of the risk of all non-vertebral and hip fractures, strontium } \\
\text { ranelate offers a safe and effective means of reducing the risk of fracture associat- } \\
\text { ed with osteoporosis }\end{array}$ \\
\hline 16 & Roux & 2016 & In Vivo/Women & Vertebral antifracture efficacy, Efficacy of antiosteoporotic \\
\hline 17 & Ammann et al. [4] & 2004 & In Vivo/Rats & $\begin{array}{l}\text { Improves bone resistance, Increasing bone mass, Improving architecture, Main- } \\
\text { taining bone stiffness }\end{array}$ \\
\hline 18 & Reginster & 2008 & In Vivo/Women & Reduction in the incidence of osteoporotic nonvertebral fractures \\
\hline 19 & Meunier et al. [5] & 2004 & In Vivo/Women & Reductions in the risk of vertebral fractures \\
\hline 20 & Bruyere & 2007 & In Vivo/Women & $\begin{array}{l}\text { Increase in femoral neck BMD } \\
\text { Reduction in vertebral fracture incidence }\end{array}$ \\
\hline 21 & Choudhary et al. [16] & 2007 & In Vitro & $\begin{array}{l}\text { Significantly increased ALP activity, Increased ALP and OCN mrna expression, } \\
\text { Increased mineralization after, Dose-dependently increased PGE2 production, } \\
\text { Stimulation of mineralization }\end{array}$ \\
\hline
\end{tabular}




\section{Action Mechanisms of Strontium Ranelate}

The exact mechanism by which strontium ranelate exerts these effects is not definitely understood, but may include inhibition of osteoclast formation and stimulation of osteoblast proliferation [46]. Strontium ranelate has the atomic number 38 and the atomic symbol Sr, belongs to the group II in the periodic table of the elements, just beneath $\mathrm{Ca}+2$ (Figures $1 \& 2$ ). As its nucleus is similar to that of $\mathrm{Ca}+2$, the body takes up strontium into tooth enamel and bones in the place of $\mathrm{Ca}+2$. In addition Strontium ranelate stimulates the $\mathrm{Ca}+2$ sensing receptors [47]. Strontium ranelate regulates protein and mRNA levels of the osteoblast which induced signals for osteoclastogenesis [48]. These findings provide new insights to the action mechanism of strontium ranelate in the bone microenvironment [49].

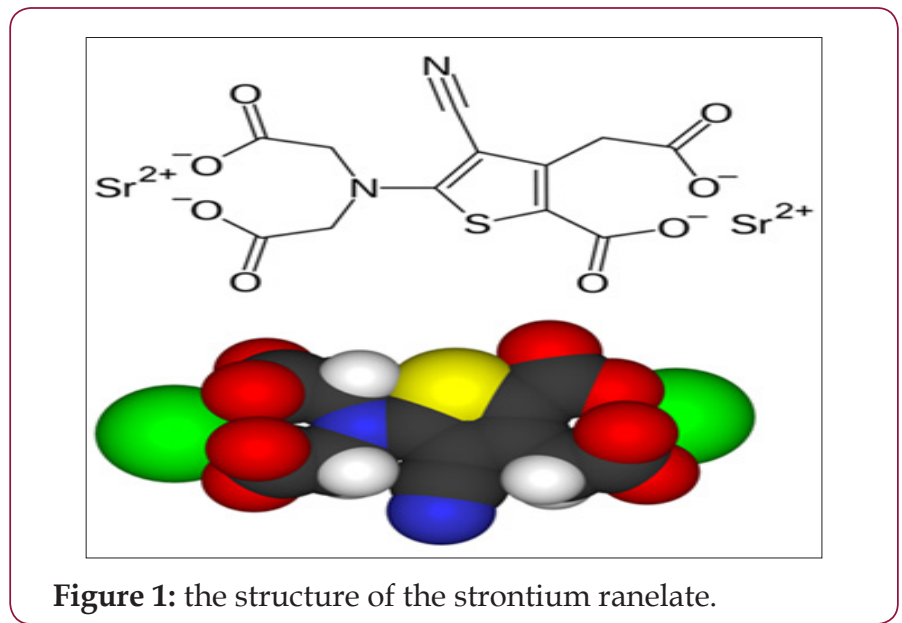

Figure 1: the structure of the strontium ranelate.

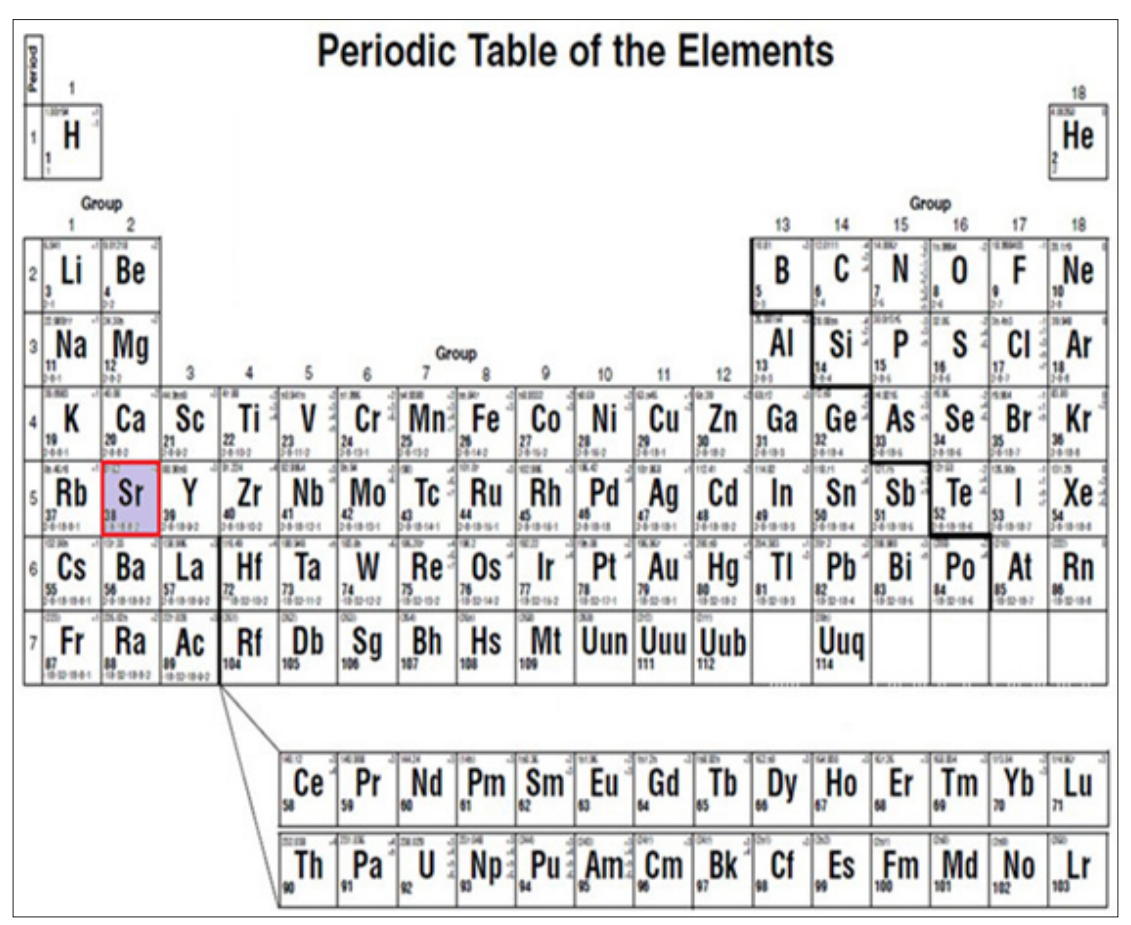

Figure 2: Strontium ranelate has the atomic number 38 and the atomic symbol Sr, belongs to the group II in the periodic table of the elements.

The cellular mechanism which strontium ranelate may act is unknown, although the inductions of activation of the Ca+2-sensing receptor and cellular differentiation have been suggested as contributing factors [50]. Previously was shown strontium suppressing the release of parathyroid hormone [51]; but recently, it has been shown to activate the $\mathrm{Ca}+2$-sensing receptor in other cell systems. Whether the $\mathrm{Ca}+2$-sensing receptor also mediates some of the effects of strontium ranelate on bone, as it reportedly does for $\mathrm{Ca}+2$, remains to be determined [52]. The fact that strontium ranelate contained in bone is eliminated in the end of treatment; it is strongly suggests which strontium ranelate was not trapped in hydroxyapatite [53]. So, in the bone mineral phase, strontium ranelate is located in the hydrated layer and can structurally modify the bone matrix in relation to the hydration state of the bony tissue (Figures 1 \& 2).

\section{Disadvantage of Strontium Ranelate}

We collected information about the risks of adverse events with the use of strontium ranelate for the treatment of postmenopausal osteoporosis [54]. In most cases of strontium ranelate did not seem to be associated with series adverse events and most adverse events were mild and transient [55]. Also the most of subsequent publications generated from the strontium clinical trials programme failed to report data on these adverse events [22]. However, it has been reported which there is a higher rate of cardiac events (myocardial infarction) in men with to strontium ranelate therapy. The 2013 Periodic Safety Update Report showed that strontium increased the risk of myocardial infarction in pooled analyses in postmenopausal women [56]. The risk of two serious adverse event, venous thromboembolism and pulmonary embolism was found to be significantly higher in patients with strontium ranelate therapy [5]. 
Some nervous system disorders, including disturbed consciousness, seizures, mental impairment, and memory loss and were reported with the use of strontium ranelate [57]. Strontium ranelateis associated with a number of other risks, such as serious disturbances in consciousness, liver inflammation, seizures, gastrointestinal disturbance, reduced number of blood cells, severe skin reactions such as Stevens-Johnson syndrome, toxic-epidermal necrosis, and drug rash with eosinophilia and systemic symptoms [58]. In the cases that we should not use strontium ranelate like stroke and ischemic cardiac events we can use efficacious drugs such as alendronate, risedronate, zoledronate, or denosumab [18]. Strontium ranelate acts through an innovative mode of action by inhibiting bone resorption and stimulating bone formation [59]. Strontium ranelate is a new drug for the treatment of postmenopausal osteoporosis and its safety profile is not fully established [60]. Strontium ranelate has been associated with adverse events and idiosyncratic reactions [61]. Strontiumranelate has been studied in many studies for a longer duration. So, it's pre-marketing safety data are relatively robust [49].

\section{Conclusion}

It seems that Strontium ranelate is aeffective and winsome treatment for osteoporosis and in the most cases the side effect of this drug is negligible.

\section{References}

1. Brandt KD, Mazzuca SA, Katz BP, Lane KA, Buckwalter KA, et al. (2005) Effects of doxycycline on progression of osteoarthritis: results of a randomized, placebo-controlled, double-blind trial. Arthritis Rheum 52 2015-2025.

2. Hernlund E, Svedbom A, Ivergard M, Compston J, Cooper C, et al (2013) Osteoporosis in the European Union: medical management, epidemiology and economic burden. A report prepared in collaboration with the International Osteoporosis Foundation (IOF) and the European Federation of Pharmaceutical Industry Associations (EFPIA). Arch Osteoporos 8: 136.

3. Reginster JY, Badurski J, Bellamy N, Bensen W, Chapurlat R, et al. (2013) Efficacy and safety of strontium ranelate in the treatment of knee osteoarthritis: results of a double-blind, randomized placebo-controlled trial. Ann Rheum Dis 72(2): 179-186.

4. Ammann P, Shen V, Robin B, Mauras Y, Bonjour JP, et al. (2004) Strontium ranelate improves bone resistance by increasing bone mass and improving architecture in intact female rats. Bone Miner Res 19: 2012 2020.

5. Meunier PJ, Roux C, Seeman E, Ortolani S, Badurski JE, et al. (2004) The effects of strontium ranelate on the risk of vertebral fracture in women with postmenopausal osteoporosis. N Engl J Med 350: 459-468.

6. Varkey M, Kucharski C, Doschak MR, Winn SR, Brochmann EJ, et al. (2007) Osteogenic response of bone marrow stromal cells from normal and ovariectomized rats treated with a low dose of basic fibroblast growth factor. Tissue Eng 13: 809-817.

7. Abrahamsen B, Grove E, Vestergaard P (2014) Nationwide registrybased analysis of cardiovascular risk factors and adverse outcomes in patients treated with strontium ranelate. Osteoporosis Int 25(2): 757762.

8. Hengsberger S, Boivin G, Zysset PK (2002) Morphological and mechanical properties of bone structural units: A two-case study. Jap Soc Mechan EnginSer C 45(4): 936-943.
9. Baron R, Tsouderos Y (2002) In vitro effects of S12911-2 on osteoclast function and bone marrow macrophage differentiation. Eur J Pharmacol 450(1): 11-17.

10. Takahashi N, Sasaki N, Tsouderos Y, Suda T (2003) S12911-2 inhibits osteoclastic bone resorption in vitro. Bone Miner Res 18(6): 1082-1087.

11. Barbara A, Delannoy P, Denis BG, Marie PJ (2004) Normal matrix mineralization induced by strontium ranelate in MC3T3-E1 osteogenic cells. Metabolism 53(4): 532-537.

12. Sun K, Liu J, Sun H, Lu N, Ning G (2013) Bisphosphonate treatment and risk of esophageal cancer: a meta-analysis of observational studies. Osteoporosis Int 24(1): 279-286.

13. Bolland MJ, Barber A, Doughty RN (2013) Differences between selfreported and verified adverse cardiovascular events in a randomised clinical trial. BMJ Open 3: 002334.

14. Fromigue O, Barbara A, Hay E, Petrel C, Traiffort E, et al. (2006) Strontium ranelate stimulates murine osteoblast replication independently of calcium sensing receptor mediated ERK1/2 activation. Calcif Tissue Int 78: S145.

15. Black DM, Greenspan SL, Ensrud KE, Lisa Palermo, Joan A McGowan, et al. (2003) The effects of parathyroid hormone and alendronate alone or in combination in postmenopausal osteoporosis. N Engl J Med 349: 1207-1215.

16. Choudhary S, Wadhwa S, Raisz LG, Alander C, Pilbeam CC (2003) Extracellular calcium is a potent inducer of cyclooxygenase-2 in murine osteoblasts through an ERK signaling pathway. Bone Miner Res 18 (10): 1813-1824.

17. Purpura KA, Zandstra PW, Aubin JE (2003) Fluorescence activated cell sorting reveals heterogeneous and cell nonautonomousosteoprogenitor differentiation in fetal rat calvaria cell populations. Cell Biochem 90(1): 109-120.

18. Reginster JY (2002) Strontium ranelate in osteoporosis. Curr Pharm Des 8(21): 1907-1916.

19. Reginster JY, Slosman DO, Delmas PD, Sebert JL, Brandi ML, et al. (2001) Strontium ranelate: Dose-dependent effects in postmenopausal osteoporosis: The STRATOS 2-year randomized trial. Clin Rheumatol 20: OP22.

20. Okada Y, Tomita M, Gronowicz G, Kawaguchi HJS, Tanaka M, et al. (2000) Effects of cyclooxygenase-2 gene disruption on osteoblastic function. Bone Miner Res 15: S217.

21. Yang L, Tian J, He Z, Tang X, Yang K (2013) A Meta-analysis of alendronate for the prevention and treatment of glucocorticoid induced osteoporosis. Zhonghua NeiKeza Zhi 52: 838-843.

22. Kaufman JM, Audran M, Bianchi G, Braga V, Diaz-Curiel M, et al. (2013) Efficacy and safety of strontium ranelate in the treatment of osteoporosis in men. ClinEndocrinolMetab 98(2): 592-601.

23. Boonen S, Reginster JY, Kaufman JM (2012) Efficacy of once-yearly zoledronic acid $5 \mathrm{mg}$ in men with osteoporosis with different levels of serum total testosterone [Abstract OC32]. Osteoporos Int 23(2): S79 $-\mathrm{S} 80$.

24. Brennan TC, Rybchyn MS, Conigrave AD, Mason RS (2006) Srontiumranel are effect on proliferation and OPG expression in osteoblasts. Calcif Tissue Int 78: S129.

25. Cooper C, Fox K, Borer J (2014) Ischaemic cardiac events and use of strontium ranelate in postmenopausal osteoporosis: a nested casecontrol study in the CPRD. Osteoporosis Int 25(2): 737-745.

26. Gotzsche PC (2011) Why we need easy access to all data from all clinical trials and how to accomplish it. Trials 12: 249.

27. Vestergaard P, Schwartz K, Rejnmark L, Mosekilde L, Pinholt E (2012) Oral bisphosphonate use increases the risk for inflammatory jaw disease: a cohort study. Oral Maxillofacial Surg 70(4): 821-829. 
28. Neer RM, Arnaud CD, Zanchetta JR, Prince R, Gaich GA, et al. (2001) Effect of parathyroid hormone (1-34) on fractures and bone mineral density in postmenopausal women with osteoporosis. N Engl J Med 344(19): 1434-1441.

29. Black DM, Thompson DE, Bauer DC, Ensrud K, Musliner T, et al. (2000) Fracture risk reduction with alendronate in women with osteoporosis: The Fracture Intervention Trial. FIT Research Group. Clin Endocrinol Metab 85(11): 4118-4124.

30. McClung MR, Geusens P, Miller PD, Zippel H, Bensen WG, et al. (2001) Hip Intervention Program Study Group. Effect of risedronate on the risk of hip fracture in elderly women. Hip Intervention Program Study Group. N Engl J Med 344: 333-340.

31. Marcus R, Wang O, Satterwhite J, Mitlak B (2003) The skeletal response to teriparatide is largely independent of age, initial bone density, and prevalent vertebral fractures in postmenopausal women with osteoporosis. Bone Miner Res 18(1): 18-23.

32. Ensrud KE, Thompson DE, Cauley JA, Nevitt MC, Kado DM, et al. (2000) Prevalent vertebral deformities predict mortality and hospitalization in older women with low bone mass. Fracture Intervention Trial Research Group. Am Geriatr Soc 48(3): 241-249.

33. Coulombe J, Faure H, Robin B, Tsouderos Y, Ruat M (2002) Activation of the rat and mouse cation-sensing receptor by strontium ranelate and its modulation by extracellular calcium. Osteoporos Int 13(1): P70MO.

34. Cummings RS, Melton LJ (2002) Epidemiology and outcomes of osteoporotic fractures. Lancet 359(9319): 1761-1767.

35. Pi M, Quarles LD (2004) A novel cation-sensing mechanism in osteoblasts is a molecular target for strontium. Bone Miner Res 19(5): 862-869.

36. Manabe T, Mori S, Mashiba T (2007) Human parathyroid hormone (1-34) accelerates natural fracture healing process in the femoral osteotomy model of cynomolgus monkeys. Bone 40(6): 1475-1482.

37. Gaston MS, Simpson AHRW (2007) Inhibition of fracture healing. Bone Joint Surg (Br) 89(12): 1553-1560.

38. Inderjeeth CA, Foo ACH, Lai MMY (2009) Efficacy and safety of pharmacological agents in managing osteoporosis in the old: Review of the evidence. Bone 44(5): 744-751.

39. Giannoidus P, Tzioupis C, Almalki T (2007) Fracture healing in osteoporotic fractures: is it really different? A basic science perspective. Injury 38: 90-99.

40. Barenholdt O, Kolthoff N, Nielsen SP (2009) Effect of longterm treatment with strontium ranelate on bone strontium content. Bone 45(2): 200206.

41. Caverzasio J (2008) Strontium ranelate promotes osteoblastic cell replication through at least two different mechanisms. Bone 42(6): 1131-1136.

42. Chattopadhyay N, Quinn SJ, Kifor O (2007) The calcium-sensing receptor $(\mathrm{CaR})$ is involved in strontium ranelate-induced osteoblast proliferation. Biochem Pharmacol 74(3): 438-447.

43. Marie PJ (2005) Strontium ranelate: A novel mode of action of optimizing bone formation and resorption. OsteoporosInt 16(1): 7-10.

44. Buehler J, Chappuis P, Saffar JL, Tsouderos Y, Vignery A (2001) Strontium ranelate inhibits bone resorption while maintaining bone formation in alveolar bone in monkeys (Macacafascicularis). Bone 29(2): 176-179.

45. Cauley JA, Thompson DE, Ensrud KC, Scott JC, Black D (2000) Risk of mortality following clinical fractures. OsteoporosInt 11(7): 556-561.
46. Arikawa T, Omura K, Morita I (2004) Regulation of bone morphogenetic protein-2 expression by endogenous prostaglandin E2 in human mesenchymal stem cells. Cell Physiol 200(3): 400-406.

47. Rizzoli R, Chapurlat RD, Laroche JM (2012) Effects of strontium ranelate and alendronate on bone microstructure in women with osteoporosis: results of a 2-year study. Osteoporos Int 23(1): 305-315.

48. Vestergaard P (2012) Acute myocardial infarction and atherosclerosis of the coronary arteries in patients treated with drugs against osteoporosis: calcium in the vessels and not the bones? Calcified Tissue Int $90(1): 22-29$.

49. Tengvall P, Skoglund B, Askendal A (2004) Surface immobilized bisphosphonate improves stainless-steel screw fixation in rats. Biomaterials 25(11): 2133-2138.

50. Gabet Y, Muller R, Levy J (2006) Parathyroid hormone 1-34 enhances titanium implant anchorage in low-density trabecular bone: as correlative micro-computed tomographic and biomechanical analysis. Bone 39(2): 276-282.

51. Andreassen TT, Fledelius C, Ejersted C (2001) Increases in callus formation and mechanical strength of healing fractures in old rats treated with parathyroid hormone. Acta Orthop Scand 72(3): 304-307.

52. Chen TL (2004) Inhibition of growth and differentiation of osteoprogenitors in mouse bone marrow stromal cell cultures by increased donor age and glucocorticoid treatment. Bone 35(1): 83-95.

53. Sambrook P, Roux C, Devogelaer J, Saag K, Lau C, et al. (2012) Bisphosphonates and glucocorticoid osteoporosis in men: results of a randomized controlled trial comparing zoledronic acid with risedronate. Bone 50(1): 289-295.

54. Lampropoulou K, Tournis S, Balanika A, Antoniou I, Stathopoulos I, et al. (2013) Sequential treatment with teriparatide and strontium ranelate in a postmenopausal woman with atypical femoral fractures after long-term bisphosphonate administration. Hormones (Athens, Greece) 12(4): 591-597.

55. Canalis E, Bilezikian JP, Angeli A, Giustina A (2004) Perspectives on glucocorticoid-induced osteoporosis. Bone 34(4): 593-598.

56. Feldstein AC, Nichols GA, Elmer PJ, Smith DH, Aickin M, et al. (2003) Older women with fractures: Patients falling through the cracks of guideline-recommended osteoporosis screening and treatment. Bone Joint Surg Am 85(12): 2294-2302.

57. Briancon D, de Gaudemar JB, Forestier R (2004) Management of osteoporosis in women with peripheral osteoporotic fractures after 50 years of age: A study of practices. Joint Bone Spine 71(2): 128-130.

58. Diez-Perez A, Adachi J, Agnusdei D, Bilezikian J, Compston J, et al. (2012) Treatment failure in osteoporosis. Osteoporosis International 23(12): 2769-2774.

59. Dahl SG, Allain P, Marie PJ, Mauras Y, Boivin G, et al. (2001) Incorporation and distribution of strontium in bone. Bone 28(4): 446-453.

60. Autier P, Haentjens P, Bentin J, Baillon JM, Grivegnee AR, et al. (2000) Costs induced by hip fractures: A prospective controlled study in Belgium. Belgian Hip Fracture Study Group. OsteoporosInt 11(5): 373380 .

61. Chesnut CH, Rosen CJ (2001) Reconsidering the effects of antiresorptive therapies in reducing osteoporotic fracture. J Bone Miner Res 16(12): 2163-2172. 
(c) (1) This work is licensed under Creative Submission Link: https://biomedres.us/submit-manuscript.php

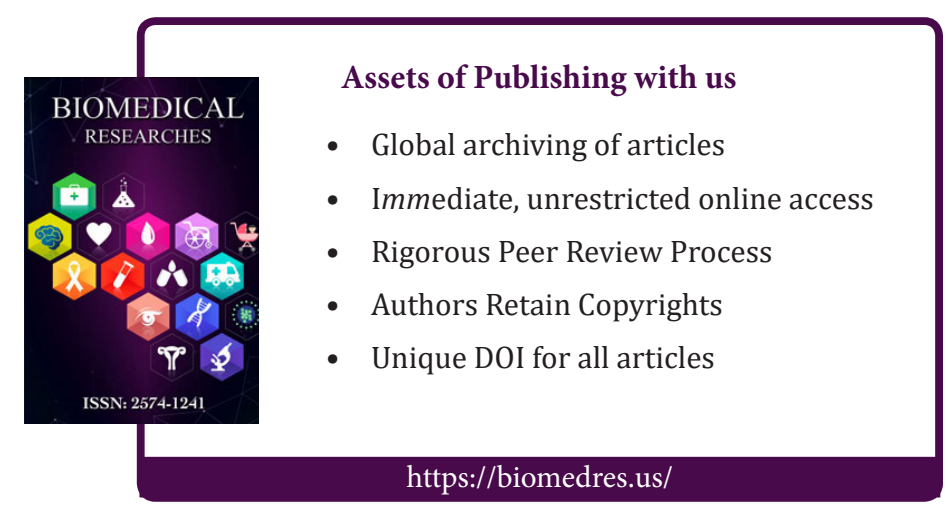

